\title{
Evaluation of insulin resistance improvement after laparoscopic sleeve gastrectomy or gastric bypass surgery with HOMA-IR
}

\author{
Yubing Zhu ${ }^{\S}$, Zhipeng Sun ${ }^{\S}$, Yanmin Du, Guangzhong Xu, Ke Gong, Bin Zhu, Nengwei Zhang* \\ Diabetes Surgery Centre, General Surgery Department, Peking University Ninth School of Clinical Medicine (Beijing Shijitan \\ Hospital, Capital Medical University), Beijing, China.
}

\begin{abstract}
Summary Our purpose was to explore the remission of insulin resistance after bariatric surgery to discover the mechanism of diabetes remission excluding dietary factors. A retrospective case control study was conducted on patients with type 2 diabetes, who underwent laparoscopic sleeve gastrectomy (LSG) or laparoscopic gastric bypass surgery (LGB) in Beijing Shijitan Hospital from April 1, 2012 to April 1, 2013. The laboratory and anthropometric data was analyzed pre-surgery and during a 2-year follow-up. HOMA-IR was calculated and evaluated. The two surgical procedures were compared. No significant difference in complete remission rate was observed between the two groups (LGB group: 62.1\%, LSG group: 60.0\%, $p=0.892)$. HOMA-IR was reduced to a stable level at the $3^{\text {rd }}$ month after surgery. The cut-off value of HOMA-IR was 2.38 (sensitivity: 0.938 , specificity: 0.75 ) and 2.33 (sensitivity: 0.941 , specificity: 0.778 ) respectively for complete remission after LSG or LGB surgery. Insulin resistance was improved while GLP-1 and Ghrelin was changed significantly in patients with type 2 diabetes prior to weight loss either in the LSG or LGB group. HOMA-IR decreased to less than the cut-off value at the $3^{\text {rd }}$ month and was closely related to complete remission. The mechanism of bariatric surgery was not due just to simply dietary factors or body weight loss but also the remission of insulin resistance.
\end{abstract}

Keywords: Laparoscopic sleeve gastrectomy (LSG), laparoscopic gastric bypass (LGB), type 2 diabetes, homeostasis model of insulin resistance index (HOMA-IR)

\section{Introduction}

Currently, the procedures for treatment of diabetic mellitus with bariatric surgery mainly consists of 3 categories: surgeries for intake restriction, surgeries for poor absorption and surgeries with both effects. The intake restriction surgeries mainly include laparoscopic adjustable gastric banding and laparoscopic sleeve gastrectomy (LSG); the surgeries causing poor absorption mainly includes the laparoscopic biliopancreatic diversion; and the third classification have both the restriction and mal-absorption effects, including laparoscopic gastric bypass (LGB) (1).

\footnotetext{
${ }^{\$}$ These authors contributed equally to this work.

*Address correspondence to:

Dr. Nengwei Zhang, Vice president of Chinese Society for Metabolic \& Bariatric Surgery (CSMBS). Peking University Ninth School of Clinical Medicine (Beijing Shijitan Hospital, Capital Medical University). Tieyilu 10, Yangfangdian, Haidian District, Beijing 10038, China.

E-mail: zhangnw1@sohu.com
}

In the general view of most people, the reasons for the therapeutic effects concerning diabetes by the three kinds of surgeries were due to the intake reduction or mal-absorption, not improvement of insulin resistance or islet function (2). Although some animal experiments showed that insulin resistance may be relieved after gastrointestinal bypass surgery (3). However, there was still no clinical study about evaluation of insulin resistance improvement after bariatric surgery.

In clinical practice, the common homeostasis model of insulin resistance index (HOMA-IR) was used to evaluate insulin resistance and functions of islet $\beta$ cells. The results are significantly associated with the "gold standard", the glucose clamp results (4). The standard of insulin resistance index (HOMA-IR) was different in every race, every country (5-14) . The cut-off values of HOMA-IR in a specific population should be defined, so that, we could know whether someone's HOMA-IR was normal or not $(7,15)$. But, until now there wasn't any definite cut-off value of HOMA-IR for the adult Chinese population (Table 1). 
Table 1. Main cut-off values of HOMA-IR in recent literatures

\begin{tabular}{|c|c|c|c|c|}
\hline Location and time & Sample size & Population characteristics & Threshold value & Criteria \\
\hline Sweden, 2000 (5) & $n=4,816$ & Health population & 2.0 & $75^{\text {th }}$ percentile \\
\hline France, $2002(6)$ & $n=1,153$ & Age: $35-64$; Health population & 3.8 & $75^{\text {th }}$ percentile \\
\hline Caucasus, $2006(8)$ & $n=1,156$ & Rural population; Non-diabetic & 2.29 & $75^{\text {th }}$ percentile \\
\hline Brazil, 2006 (7) & $n=1,317$ & Age: $40 \pm 12 ;$ BMI: $34 \pm 10 \mathrm{~kg} / \mathrm{m}^{2}$ & 2.77 & $90^{\text {th }}$ percentile \\
\hline U.S., $2008(9)$ & $n=2,804$ & Age $\geq 20$; normal BMI and fasting glucose & 2.73 & $66^{\text {th }}$ percentile \\
\hline Iran, $2010(10)$ & $n=3,071$ & Adult individuals; age: 25 - 64 & 3.875 & ROC curve \\
\hline Iran, $2011(11)$ & $n=1,036$ & Women individuals selected from among reproductive aged & 2.63 & $95^{\text {th }}$ percentile \\
\hline Japan, 2012 (12) & $n=6,868$ & Non-diabetic subjects & 1.7 & $\mathrm{ROC}$ \\
\hline China, 2013 (13) & $n=3,203$ & Age: 6 - 18 (children and teenagers) & 3.0 & $95^{\text {th }}$ percentile \\
\hline Portugal, 2014 (14) & $n=1,784$ & $\begin{array}{l}\text { Non-diabetic individuals in a cardiology ward; BMI }<25 \mathrm{Kg} / \mathrm{m}^{2} \text {; } \\
\mathrm{FPG}<100 \mathrm{mg} / \mathrm{dL}\end{array}$ & 2.33 & $90^{\text {th }}$ percentile \\
\hline
\end{tabular}

The main purpose of this article was to analyze the remission effect of insulin resistance after LGB or LSG procedures through specific HOMA-IR cut-off values, to illustrate the curative mechanism of bariatric surgery excluding dietary factors.

\section{Materials and Methods}

The study was performed in accordance with the Declaration of Helsinki of the World Medical Association and was approved by the Beijing Shijitan Hospital, Capital Medical University. All patients signed an informed consent form for this investigation.

\subsection{Subjects}

The study included 67 patients with type 2 diabetes who underwent bariatric surgery in Diabetes Surgery Centre, Beijing Shijitan Hospital from April 1, 2012 to April 1, 2013. Patients who underwent laparoscopic sleeve gastrectomy were included in the LSG group $(n=35)$, while patients who underwent laparoscopic Roux-en-Y gastric bypass surgery were included in the LGB group $(n$ $=32$ ).

The criteria for the diagnosis of type 2 diabetes (T2DM) was in accordance with American Diabetes Association (ADA 2013) criteria (16).

\subsubsection{Inclusion Criteria}

Surgical indications were based on recommended criteria in the 2011 Chinese Expert Consensus on Surgical Treatment of Type 2 diabetes, including: (1) BMI $\geq 28 \mathrm{~kg} / \mathrm{m}^{2}$; (2) The patients aged $\leq 65$ years; (3) The duration of diabetes $\leq 15$ years; (4) Islet function above half of the normal lower limit.

\subsubsection{Exclusion Criteria}

(1) Type 1 diabetes disease. (2) Stress-induced hyperglycemia; hyperglycemia caused by liver disease, kidney disease or endocrine diseases; acromegaly; hyperthyroidism; drug-induced hyperglycemia. (3)
Significant organ dysfunctions resulting in disability to tolerate surgery. (4) Islet function below half of the normal lower limit.

\subsection{Methods}

All patients were followed up for two years. Laboratory tests and anthropometric indexes were followed up and retrospective comparisons were taken.

\subsubsection{Anthropometric indexes and laboratory indexes}

Body mass index $(\mathrm{BMI})=$ weight $/$ height squared $\left(\mathrm{kg} / \mathrm{m}^{2}\right)$. Percentage of excess weight loss (EWL $\%)=($ preoperative weight - postoperative weight $) /$ (preoperative weight - ideal body weight) $* 100 \%$ (ideal BMI $=25 \mathrm{~kg} / \mathrm{m}^{2}$ for Chinese population).

Insulin was measured with radio-immuno-assay (RIA) method, HbA1c measured with chromatography, and plasma glucose level measured with hexokinase enzymatic reference method (17). The formula of HOMA homeostasis mode: HOMA-IR = fasting insulin $(\mathrm{mU} /$ $\mathrm{mL})$ * fasting glucose $(\mathrm{mmol} / \mathrm{L}) / 22.5$, HOMA- $\beta=20$ * fasting insulin $(\mathrm{mU} / \mathrm{mL}) /$ (fasting plasma glucose $(\mathrm{mmol} /$ L) - 3.5).

The cut-off value of HOMA-IR was 1.55 for men or 2.22 for women (18) which means patients with HOMA-IR $\geq 1.55$ for men or HOMA-IR $\geq 2.22$ for women were identified as insulin resistant, with HOMA-IR $<1.55$ for men or HOMA-IR $<2.22$ for women as within normal limit. In regard to definitions of "complete response" and "partial response", we used the experts consensus of the American Diabetes Association (ADA) in 2013 (16): the partial response was defined as $\mathrm{HbA} 1 \mathrm{c}<6.5 \%$, and fasting plasma glucose: $5.6-6.9 \mathrm{mmol} / \mathrm{L}$ for at least 1 year, under conditions of not receiving any medical and surgical treatment. The complete response was defined as $\mathrm{HbA} 1 \mathrm{c}<6.0 \%$, and fasting plasma glucose $<$ $5.6 \mathrm{mg} / \mathrm{dL}$ for at least 1 year, under conditions of not receiving any medical and surgical treatment. Complete response for over 5 years was defined as consistent response (19). 


\subsubsection{Pre-surgery and follow-up examinations}

Medical history collection, physical examinations, routine laboratory tests (blood cell analysis, liver function, kidney function, blood lipids, blood glucose, blood clotting, stool, urine), endocrine assessment (thyroid function, catecholamine, growth hormone, cortisol), diabetes-related tests (hemoglobin A1c (HbA1C), oral glucose tolerance test (OGTT), insulin stimulation test, $\mathrm{C}$ peptide stimulation test), nutritional assessment (vitamin $\mathrm{B}_{12}$, folic acid, vitamin $\mathrm{D}$, serum iron), glucagon-like peptide-1 (GLP-1), Ghrelin, abdomen CT, gastrointestinal imaging, gastroscope, helicobacter pylori tests (in case of any abnormal conditions, providing treatment until normal), electrocardiogram (ECG), respiration monitoring during sleep, consultation from the related department in case of any comorbidities, and surgical risk assessment were taken before surgery.

\subsubsection{Operative procedure}

One bariatric surgeon (Nengwei Zhang) performed all the bariatric procedures at Beijing Shijitan Hospital, and their patients comprised the cohort included in this study.

For LGB surgery, all jejuno-jejunostomy anastomoses were created using a stapled technique with a 60-mm cartridge. Gastrojejunostomy was in a sideto-side anastomosis using a linear stapler and a double layer running closure with a 3-0 VICRYL suture under the ante-colic approach with closure of the mesenteric defect.

LSG surgery was performed using a Gastroscope (12.5 mm diameter) as a stent. The staple line was created using a stapled technique with a $60-\mathrm{mm}$ cartridge.

\subsection{Statistical analysis}

SPSS19.0 software was used for statistical analysis of the experimental data. Normal distribution continuous variables were presented as the mean \pm standard deviation; non-normal distributed variables were presented as median (range), and the categorical variables were presented as percentages. The $t$ test was used for comparison of means between groups; $\chi^{2}$ test or Fisher's exact test was used for comparison of categorical data between groups; $P<0.05$ was considered statistically significant for all tests.

\section{Results}

67 patients completed the 2-year follow-up among the 82 patients. 15 patients were lost to follow-up (18.2\%). Among them, 10 patients $(66.7 \%)$ were contacted by telephone. The major reason of loss to follow-up was busy work schedule (30\%), family issues $(20 \%)$, and moving to other city or country $(20 \%)$. The mean age of the 67 patients that finished the follow-up was 43.5 \pm 7.6 years old, and the BMI pre-surgery was $36.5 \pm 6.8$ $\mathrm{kg} / \mathrm{m}^{2}$ on average. The baseline values of the patients between the two groups did not show any significant difference (Table 2).

Two years after the operation, the patients in both groups showed a successful effect of weight-loss. EWL\% increased from the $1^{\text {st }}$ month after surgery to the $12^{\text {th }}$ month, then it reached a platform stage. EWL\% was $77.8 \%$ in the LSG group, and $76.2 \%$ in the LGB group at the $2^{\text {nd }}$ year after surgery. The LSG group showed a more significant effect of weight loss at the $3^{\text {rd }}, 6^{\text {th }}$, and $9^{\text {th }}$ month after surgery $(P=0.026,0.039$, 0.046). In the subsequent follow-up, the patients in both groups showed stable effects of weight loss, without a significant difference in EWL\% (Figure1).

During the 2 years follow-up after the operation, the partial curative rate was $72.9 \%$ in the LGB group and $67.5 \%$ in the LSG group, $p=0.355$. The complete response rates of diabetic mellitus were $62.1 \%$ in the LGB group and $60 \%$ in the LSG group, and no significant difference was found between the two groups $(p=0.892)$ (Table 3$)$. According to the cutoff values of insulin resistance reported (18), all the patients had various extents of insulin resistance presurgery, the mean value of HOMA-IR was 4.8 (3.8-7.6). It declined from the $1^{\text {st }}$ month follow-up after surgery. At the $3^{\text {rd }}$ month after surgery, the insulin resistance

Table 2. The baseline values * of the patients between the LGB and LSG group

\begin{tabular}{lccc}
\hline Iterms & LGB $(n=35)$ & LSG $(n=32)$ & $P$ value \\
\hline Age (Year) & $39.5 \pm 11.8$ & $42.3 \pm 12.8$ & 0.453 \\
Gender (Male, \%) & 47.1 & 41.4 & 0.947 \\
Weight $(\mathrm{Kg})$ & $86.2 \pm 13.3$ & $39 \pm 23$ & 0.644 \\
BMI $\left(\mathrm{Kg} / \mathrm{m}^{2}\right)$ & $36.7 \pm 4.6$ & $9.8 \pm 6.3$ & 0.927 \\
Fasting plasma glucose (mg/dL) & $8.1(6.5,10.5)$ & $13(9.7,21.6)$ & 0.228 \\
Fasting insulin (mU/mL) & $11.5(8.5,15)$ & $5.7(4.5,8.2)$ & 0.311 \\
HOMA-IR & $4.3(3.2,5.8)$ & $45.6(25.1,81.1)$ & 0.064 \\
HOMA- $\beta$ & $53.3(28.8,91.2)$ & $7.9(6.9,8.7)$ & 0.733 \\
HbAlc $(\%)$ & $6.9(6.2,7.9)$ & 0.176 & \\
\hline
\end{tabular}

"Normal distribution continuous variables were presented as the mean \pm standard deviation; non-normal distributed variables were presented as median (range), and the categorical variables were presented as percentages. 


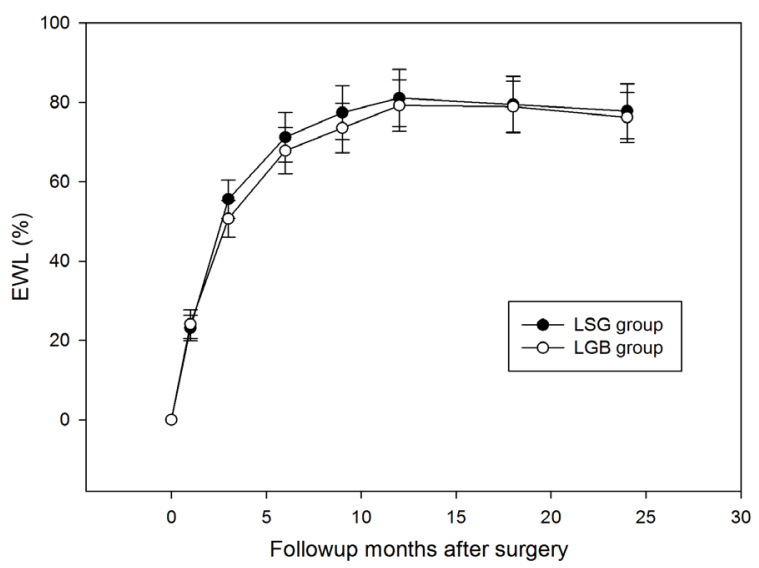

Figure 1. Decrease of EWL\% after operation (results represented as mean; Student $\boldsymbol{t}$-test, $\boldsymbol{p}<\mathbf{0 . 0 5}$ for significant difference). Two years after the operation, the patients in both groups showed a successful effect of weight-loss. The LSG group showed a more significant effect of weight loss within 6 months after the operation. In the subsequent follow-up, the patients in both groups showed stable effects of weight loss, without significant differences in EWL\%. In LSG group, the EWL \% reduction was $55.4 \%, 70.3 \%, 80.1 \%, 77.4 \%$ at the $3^{\text {rd }}$, $6^{\text {th }}, 12^{\text {th }}$, and $24^{\text {th }}$ month respectively. In the LGB group, the EWL \% reduction was $50.6 \%, 68.8 \%, 79.3 \%, 76.4 \%$ at the $3^{\text {rd }}$, $6^{\text {th }}, 12^{\text {th }}$, and $24^{\text {th }}$ month respectively. $P$ values for comparison of LSG and LGB were $0.026,0.039,0.782,0.798$ at the $3^{\text {rd }}$ month, $6^{\text {th }}$ month, $12^{\text {th }}$ month, and $24^{\text {th }}$ month respectively.

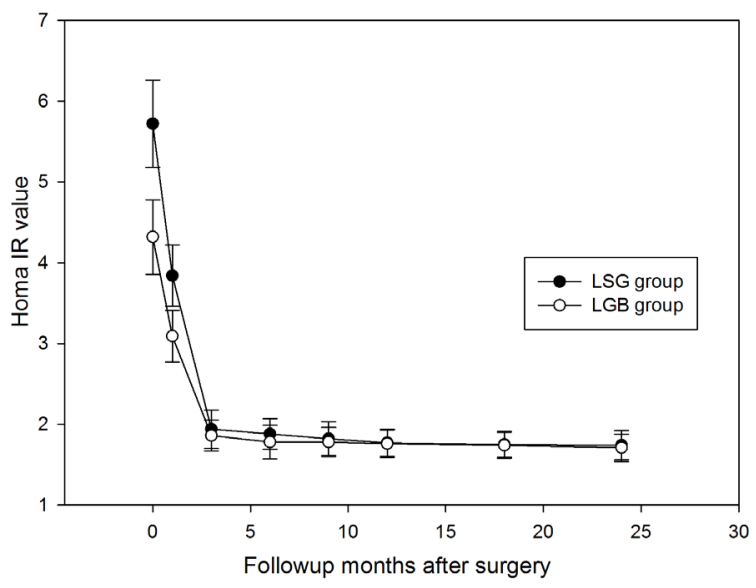

Figure 2. Change of HOMA-IR after operation (results represented as mean; Student $t$-test, $p<0.05$ for significant difference). The HOMA-IR values of patients in both groups decreased to normal limits at the $3^{\text {rd }}$ month after surgery. In the subsequent follow-up, the patients in both groups showed stable normal HOMA-IR values without significant differences. In the LSG group, the HOMA-IR value was 5.72, 1.94, 1.88, $1.51,1.74$ pre-surgery time, at the $3^{\text {rd }}, 6^{\text {th }}, 12^{\text {th }}$, and $24^{\text {th }}$ month post-surgery respectively. In the LGB group, the HOMA-IR value was $4.32,1.86,1.78,1.76,1.71$ pre-surgery, at the $3^{\text {rd }}$, $6^{\text {th }}, 12^{\text {th }}$, and $24^{\text {th }}$ month post-surgery respectively. $\mathrm{P}$ values for comparison of LSG and LGB were $0.064,0.652,0.582,0.398$, 0.638 pre-surgery, at the $3^{\text {rd }}, 6^{\text {th }}, 12^{\text {th }}$, and $24^{\text {th }}$ month postsurgery respectively.

Table 3. HOMA-IR at the $3^{\text {rd }}$ month and $2^{\text {nd }}$ year and EWL at the $2^{\text {nd }}$ year had statistical differences compared with the value before surgery

\begin{tabular}{llcc}
\hline Iterms & OR & $95 \%$ Conf. Interval & $P$ value \\
\hline Age & 0.87 & $0.85-1.21$ & 0.216 \\
HOMA-IR at 3rd month post-surgery & 1.52 & $1.16-1.9$ & 0.039 \\
EWL at 3rd month post-surgery & 1.21 & $0.88-1.21$ & 0.600 \\
HOMA-IR at 2nd year post-surgery & 1.63 & $1.35-2.16$ & 0.024 \\
EWL at 2nd year post-surgery & 1.59 & $1.25-2.08$ & 0.032 \\
\hline
\end{tabular}

index (HOMA-IR) of both groups showed significant reduction and reached a platform stage (Figure 2). The cut-off value of HOMA-IR was 2.38 (sensitivity: 0.938, specificity: 0.75 ) and 2.33 (sensitivity: 0.941, specificity: 0.778 ) respectively for complete remission after LSG or LGB surgery. HOMA-IR below the cutoff value at the $3^{\text {rd }}$ month was an important indicator for complete remission (Figure 3).

Multivariate analysis by Logistic regression also showed that the recovery of insulin resistance at the $3^{\text {rd }}$ month after the operation was an independent factor for complete remission of diabetes. At the same time weight loss was not. At the $2^{\text {nd }}$ year after surgery, both HOMA-IR and EWL\% were independent factors for cure of diabetes (Table 4).

In the meantime we also examined GLP-1 and Ghrelin in both LGB and LSG groups (Table 5). The results showed that in the LGB group, the level of GLP-1 at the $1^{\text {st }}$ month post-surgery raised significantly compared with pre-surgery $(\mathrm{F}=18.79, P<0.05)$, and then, kept stable at the $3^{\text {rd }}$ month and $6^{\text {th }}$ month postsurgery. Ghrelin in the LGB group post-surgery was a little higher than that pre-surgery, but it didn't show any statistical significance.

In the LSG group, the level of GLP-1 didn't show any change before or after surgery. But the level of Ghrelin at the $1^{\text {st }}$ month post-surgery was obviously lower than that pre-surgery, it showed statistical significance $(\mathrm{F}=23.89, P<0.05)$. And kept stable at the $3^{\text {rd }}$ month and $6^{\text {th }}$ month post-surgery.

\section{Discussion}

The current results of this study showed that the two bariatric surgery procedures, LGB and LSG, had similar efficacy as treatments for insulin resistance. The complete remission rates of the two types of bariatric surgeries were similar as well.

Insulin resistance was significantly relieved prior to a significant change of their body weights, at the $3^{\text {rd }}$ month 
A

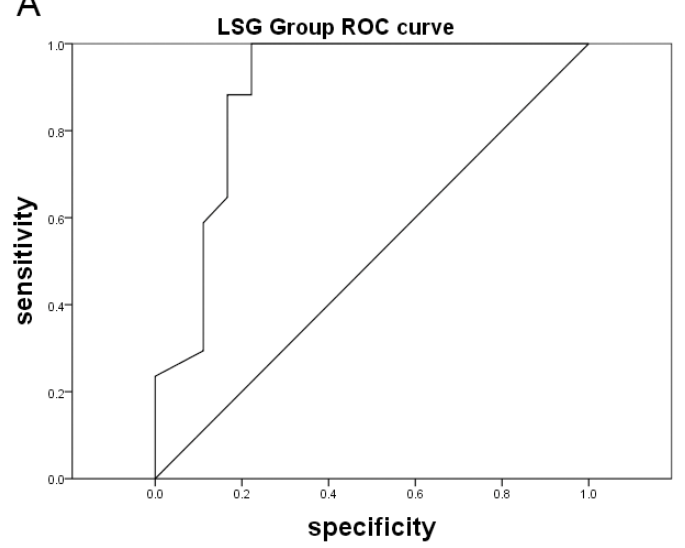

B

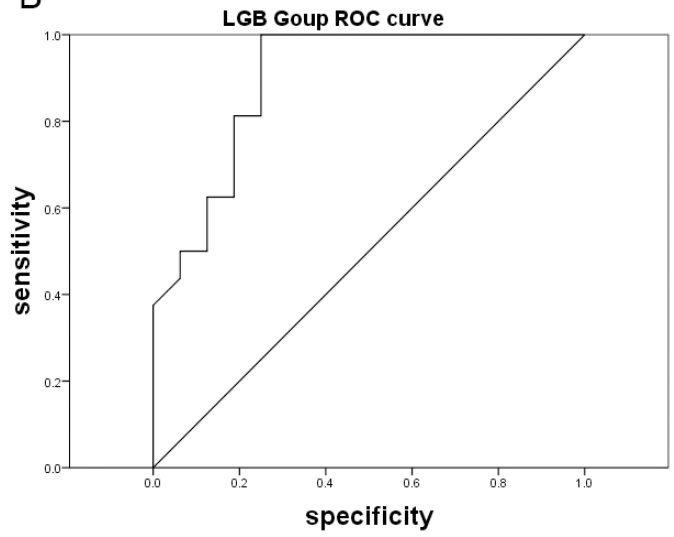

Figure 3. ROC curves for HOMA IR to predict the curable prognosis after LSG and LGB surgery respectively. A. The area under the ROC curve of HOMA-IR values in the LSG group was $0.891(95 \%$ CI: 0.773 to $1.000, P=0.001)$; the optimal cut-off value, which simultaneously maximized both the sensitivity $(94.1 \%)$ and specificity $(77.8 \%)$ of the HOMA-IR value smaller than 2.33 . B. The area under the ROC curve of HOMA-IR values in the LSG group was 0.896 (95\% CI: 0.786 to $1.000, P=0.001$ ); the optimal cut-off value, which simultaneously maximized both the sensitivity $(93.8 \%)$ and specificity $(75.0 \%)$ of the HOMA-IR value smaller than 2.38 .

Table 4 Type 2 diabetes mellitus remission and glycemic control at the $2^{\text {nd }}$ year follow-up after surgery

\begin{tabular}{lccc}
\hline Outcomes & LSG group, $n=35$ & LGB group, $n=32$ & $P$ value \\
\hline Partial remission* $^{*}$ & $26(74.3 \%)$ & $26(81.3 \%)$ & 0.08 \\
Complete remission $^{*}$ & $17(48.6 \%)$ & $16(50.0 \%)$ & 0.19 \\
\hline
\end{tabular}

"Partial remission means $\mathrm{FPG} \leq 6.9 \mathrm{mmol} / \mathrm{L}$ and $\mathrm{HbAlc}<6.5 \%$ for at least 1 year without treatment. Complete remission is defined as $\mathrm{HbA} 1 \mathrm{c}<6.0 \%$, and fasting plasma glucose $<5.6 \mathrm{mmol} / \mathrm{L}$ for at least 1 year without any medical or surgical treatment.

Table 5 The serum hormone level of GLP-1 and Ghrelin before and after surgery (mean \pm standard deviation)

\begin{tabular}{|c|c|c|c|c|c|}
\hline Outcomes & Serum hormone & Pre-surgery $(\mathrm{ng} / \mathrm{L})$ & 1 month post-surgery (ng/L) & 3 month post-surgery $(\mathrm{ng} / \mathrm{L})$ & 6 month post-surgery (ng/L) \\
\hline LSG group & GLP-1 & $65 \pm 13$ & $67 \pm 11$ & $71 \pm 15$ & $74 \pm 13$ \\
\hline$n=35$ & Ghrelin & $478 \pm 86$ & $285 \pm 62$ & $276 \pm 56$ & $268 \pm 52$ \\
\hline LGB group & GLP-1 & $66 \pm 18$ & $119 \pm 31$ & $116 \pm 28$ & $117 \pm 30$ \\
\hline$n=32$ & Ghrelin & $459 \pm 75$ & $467 \pm 83$ & $486 \pm 95$ & $501 \pm 92$ \\
\hline
\end{tabular}

after surgery. This suggested that weight loss was not the only cause of diabetes relief. Most of the previous studies found that bariatric surgeries resulted in poor absorption, such as LGB, had greater efficacy in the postoperative reduction of HOMA-IR than the restrictive surgeries, such as vertical gastric banding. This phenomenon can be explained by the mechanism of foregut and hindgut effects. The foregut effect meant avoiding food contact with the proximal jejunum reducing the gastrointestinal secretion of anti-incretin. A hindgut effect meant that the food, which is not completely digested quickly enters the distal intestine, and stimulates the distal intestine to secrete increnin, including glucagon like peptide 1 (GLP1), gastric inhibitory polypeptide (GIP) and peptide tyrosine-tyrosine (PYY) (20-22). This study showed that LSG could also cause a similar postoperative effect for the early response of insulin resistance as that with LGB. The possible reason was that LSG, as a restrictive operation, also removed the gastric fundus, which would reduce the secretion of Ghrelin. Ghrelin secreted at the gastric fundus promoted appetite and decreased the secretion of insulin and enhanced insulin resistance $(23,24)$. Therefore, inhibition of secretion of Ghrelin could also treat the diabetes and obesity (25). Meanwhile, the soft and fragment diet after both LSG and LGB had the effects of restricting energy intake and shortening the intestinal transportation time which would promote the secretion of ducdenin $(26,27)$.

For patients who had diabetes for a short duration, such as some patients in this study, insulin resistance, instead of dysfunction of beta-cells, was the major reason causing diabetes $(28,29)$. GLP-1 and Ghrelin that changed significantly and were maintained at a stable level at the $1^{\text {st }}$ month post-surgery before the change of HOMA-IR and body weight may be the reason for reduction of HOMA-IR. Enhancing insulin sensitivity was an important treatment for diabetes. In this study, the decreased HOMA-IR at the $3^{\text {rd }}$ month post-surgery showed a reduction of insulin resistance, predicating good prognosis. It is consistent with the fact 
that the normal value post-surgery of HOMA-IR is an independent predictor affecting the complete response rate after operations.

All patients in this study achieved partial remission, and approximately $60 \%$ of the patients achieved a complete response. At present, similar comparison studies between LGB and LSG showed postoperative response rates were above $80 \%$ for both procedures $(30,31)$. In our study, the relative low remission rate may be a result of the use of the remission criteria of ADA. This remission standard also requests maintaining the indicators for up to one year.

Some studies did not use the standard criteria for diabetes response, and some studies just indicated that withdrawal of drug therapy was remission; and some defined $\mathrm{HbA} 1 \mathrm{c}<6.5 \%$, fasting blood glucose levels of $<125 \mathrm{mg} / \mathrm{dL}$ without a remission duration requirement as the complete remission standard $(32,33)$. Significant errors may occur if a different response standard had been used in the comparison of the efficacy of LGB and LSG.

The limitations of the study were that it was a nonrandomized, retrospective study, in which the baseline parameters were not exactly matched between the two groups. Second, the sample size was not large which might increase sampling error. Third, the results were evaluated by HOMA-IR instead of the glucose clamp test, which was more accurate than HOMA-IR.

In summary, there were no statistical differences observed in the complete or partial remission rate of type 2 diabetes between the LSG and LGB group. In clinical practice, there was still lack of a definite and comprehensive standard for the selection of surgical styles for patients with diabetes mellitus. The metabolic surgeons chose a surgical plan according to the patient's will and interdisciplinary expertise. It is imperative to standardize the indications for surgical treatment of diabetes.

\section{Acknowledgements}

The research was funded by Beijing Municipal Administration of Hospitals Clinical Medicine Development of Special Funding Support, code: ZYLX201512. We thank the foundation and all the patients studied in this project.

\section{References}

1. Inge TH, Courcoulas AP, Jenkins TM, Michalsky MP, Helmrath MA, Brandt ML, Harmon CM, Zeller MH, Chen MK, Xanthakos SA, Horlick M, Buncher CR, Teen LC. Weight loss and health status 3 years after bariatric surgery in adolescents. N Engl J Med. 2016; 374:113-123.

2. Behary P, Miras AD. Food preferences and underlying mechanisms after bariatric surgery. Proc Nutr Soc. 2015; 74:419-425.

3. Torres A, Rubio MA, Ramos-Levi AM, Sanchez-Pernaute
A. Cardiovascular risk factors after single anastomosis duodeno-ileal bypass with sleeve gastrectomy (SADI-S): A new effective therapeutic approach? Curr Atheroscler Rep. 2017; 19:58.

4. Zhang K, Chen Y, Liu L, Lu M, Cheng J, Gao F, Wang N, Shen $\mathrm{Z}, \mathrm{Lu} \mathrm{Y}$. The triglycerides and glucose index rather than HOMA-IR is more associated with hypogonadism in Chinese men. Sci Rep. 2017; 7:15874.

5. Hedblad B, Nilsson P, Janzon L, Berglund G. Relation between insulin resistance and carotid intima-media thickness and stenosis in non-diabetic subjects. Results from a cross-sectional study in Malmo, Sweden. Diabet Med. 2000; 17:299-307.

6. Marques-Vidal P, Mazoyer E, Bongard V, Gourdy P, Ruidavets JB, Drouet L, Ferrieres J. Prevalence of insulin resistance syndrome in southwestern France and its relationship with inflammatory and hemostatic markers. Diabetes Care. 2002; 25:1371-1377.

7. Geloneze B, Repetto EM, Geloneze SR, Tambascia MA, Ermetice MN. The threshold value for insulin resistance (HOMA-IR) in an admixtured population IR in the Brazilian metabolic syndrome study. Diabetes Res Clin Pract. 2006; 72:219-220.

8. Radikova Z, Koska J, Huckova M, Ksinantova L, Imrich R, Vigas M, Trnovec T, Langer P, Sebokova E, Klimes I. Insulin sensitivity indices: A proposal of cut-off points for simple identification of insulin-resistant subjects. Exp Clin Endocrinol Diabetes. 2006; 114:249-256.

9. Sumner AE, Cowie CC. Ethnic differences in the ability of triglyceride levels to identify insulin resistance. Atherosclerosis. 2008; 196:696-703.

10. Esteghamati A, Ashraf H, Khalilzadeh O, Zandieh A, Nakhjavani M, Rashidi A, Haghazali M, Asgari F. Optimal cut-off of homeostasis model assessment of insulin resistance (HOMA-IR) for the diagnosis of metabolic syndrome: Third national surveillance of risk factors of non-communicable diseases in Iran (SuRFNCD-2007). Nutr Metab (Lond). 2010; 7:26.

11. Zadeh-Vakili A, Tehrani FR, Hosseinpanah F. Waist circumference and insulin resistance: A community based cross sectional study on reproductive aged Iranian women. Diabetol Metab Syndr. 2011; 3:18.

12. Yamada C, Moriyama K, Takahashi E. Optimal cutoff point for homeostasis model assessment of insulin resistance to discriminate metabolic syndrome in nondiabetic Japanese subjects. J Diabetes Investig. 2012; 3:384-387.

13. Yin J, Li M, Xu L, Wang Y, Cheng H, Zhao X, Mi J. Insulin resistance determined by Homeostasis Model Assessment (HOMA) and associations with metabolic syndrome among Chinese children and teenagers. Diabetol Metab Syndr. 2013; 5:71.

14. Timoteo AT, Miranda F, Carmo MM, Ferreira RC. Optimal cut-off value for homeostasis model assessment (HOMA) index of insulin-resistance in a population of patients admitted electively in a Portuguese cardiology ward. Acta Med Port. 2014; 27:473-479.

15. Tang Q, Li X, Song P, Xu L. Optimal cut-off values for the homeostasis model assessment of insulin resistance (HOMA-IR) and pre-diabetes screening: Developments in research and prospects for the future. Drug Discov Ther. 2016; 9:380-385.

16. American Diabetes A. Standards of medical care in diabetes - 2013. Diabetes Care. 2013; 36 Suppl 1:S11-66.

17. da Fonseca-Wollheim F, Heinze KG, Liss E. Temperature- 
dependent matrix effect in the direct enzymatic measurement of blood glucose.Eur J Clin Chem Clin Biochem. 1992; 30:371-375.

18. Gayoso-Diz P, Otero-Gonzalez A, Rodriguez-Alvarez MX, Gude F, Garcia F, De Francisco A, Quintela AG. Insulin resistance (HOMA-IR) cut-off values and the metabolic syndrome in a general adult population: Effect of gender and age: EPIRCE cross-sectional study. BMC Endocr Disord. 2013; 13:47.

19. Buse JB, Caprio S, Cefalu WT, Ceriello A, Del Prato S, Inzucchi SE, McLaughlin S, Phillips GL, 2nd, Robertson RP, Rubino F, Kahn R, Kirkman MS. How do we define cure of diabetes? Diabetes Care. 2009; 32:2133-2135.

20. Pendharkar SA, Drury M, Walia M, Korc M, Petrov MS. Gastrin-releasing peptide and glucose metabolism following pancreatitis. Gastroenterology Res. 2017; 10:224-234

21. McMillan CJ, Zapata RC, Chelikani PK, Snead EC, Cosford K. Circulating concentrations of glucagon-like peptide 1, glucose-dependent insulinotropic peptide, peptide YY, and insulin in client-owned lean, overweight, and diabetic cats. Domest Anim Endocrinol. 2016; 54:8594.

22. Belinova L, Kahleova H, Malinska H, Topolcan O, Windrichova J, Oliyarnyk O, Kazdova L, Hill M, Pelikanova T. The effect of meal frequency in a reducedenergy regimen on the gastrointestinal and appetite hormones in patients with type 2 diabetes: A randomised crossover study. PLoS One. 2017; 12:e0174820.

23. Santiago-Fernandez C, Garcia-Serrano S, Tome M, Valdes $\mathrm{S}$, Ocana-Wilhelmi L, Rodriguez-Canete A, Tinahones FJ, Garcia-Fuentes E, Garrido-Sanchez L. Ghrelin levels could be involved in the improvement of insulin resistance after bariatric surgery. Endocrinol Diabetes Nutr. 2017; 64:355-362.

24. Yardimci E, Bozkurt S, Cengiz MB, Malya FU. Comparison of weight loss, ghrelin, and leptin hormones after ligation of left gastric artery and sleeve gastrectomy in a rat model. Med Sci Monit. 2017; 23:1442-1447.

25. Okumura A, Unoki-Kubota H, Matsushita Y, Shiga T, Moriyoshi Y, Yamagoe S, Kaburagi Y. Increased serum leukocyte cell-derived chemotaxin 2 (LECT2) levels in obesity and fatty liver. Biosci Trends. 2013; 7:276-283.

26. Wang L, Hu X, Bi S, Tu W, Jing Y, Song L, Lv W, Yu R. A novel polysaccharide isolated from Litchi chinensis by using a simulated gastric medium and its immunomodulatory activity. Drug Discov Ther. 2015; 9:107-115.

27. Zhu X, Lin J, Song Y, Liu H, Zhang R, Fan M, Li Y, Tian R, Fang D. A high-carbohydrate diet lowered blood pressure in healthy Chinese male adolescents. Biosci Trends. 2014; 8:132-137.

28. McEvoy CT, Cardwell CR, Woodside JV, Young IS, Hunter SJ, McKinley MC. A posteriori dietary patterns are related to risk of type 2 diabetes: Findings from a systematic review and meta-analysis. J Acad Nutr Diet. 2014; 114:1759-1775 e1754.

29. Kotani K, Imazato T, Anzai K, Kyushu Diabetes Testing Study G. Expected role of medical technologists in diabetes mellitus education teams. Biosci Trends. 2015; 9:205-206.

30. Praveen Raj P, Bhattacharya S, Saravana Kumar S, Sabnis SC, Parthasarathi R, Swamy PDK, Palanivelu C. Comparison of effects of sleeve gastrectomy and gastric bypass on lipid profile parameters in Indian obese: A case matched analysis. Obes Surg. 2017; 27:2606-2612.

31. Shea B, Boyan W, Jr., Botta J, Ali S, Fenig Y, Paulin E, Binenbaum S, Borao F. Five years, two surgeons, and over 500 bariatric procedures: What have we learned? Obes Surg. 2017; 27:2742-2749.

32. Abusnana S, Abdi S, Tagure B, Elbagir M, Maleckas A. Bariatric surgery outcomes: A single-center study in the United Arab Emirates. Diabetes Metab Syndr Obes. 2015; 8:461-471.

33. Lakdawala MA, Bhasker A, Mulchandani D, Goel S, Jain S. Comparison between the results of laparoscopic sleeve gastrectomy and laparoscopic Roux-en-Y gastric bypass in the Indian population: A retrospective 1 year study. Obes Surg. 2010; 20:1-6.

(Received November 21, 2017; Revised December 7, 2017; Accepted December 25, 2017) 